\title{
TURISMO DE NATURALEZA EN ÁREAS PROTEGIDAS DE MÉXICO; UNA PROPUESTA DE CONSERVACIÓN, APROVECHAMIENTO Y DESARROLLO LOCAL EN EL NEVADO DE TOLUCA
}

\author{
Jessica Mariana Sánchez Jasso \\ Francisco Cebrián Abellán \\ Universidad de Castilla la Mancha
}

\section{RESUMEN}

El turismo de naturaleza en Áreas Protegidas de México se considera desde finales del siglo XX como un instrumento de desarrollo socioeconómico. Puesto que esta estrategia es relativamente novedosa para Latinoamérica, su implantación exige de un tratamiento especial y cuidadoso para cada una de las partes del sistema turístico. Se hace necesario asumir los principios de conservación y aprovechamiento sostenible. Se analiza en este caso el Parque Ecológico Ejidal de Cacalomacán, localizado dentro del Nevado de Toluca. Es una zona de interés para la conservación de la biodiversidad, en donde el turismo de naturaleza se ha convertido en una herramienta de desarrollo comunitario. La metodología empleada ha sido el Sistema Ponderado de Inventario y Evaluación de Recursos.

Palabras claves: Turismo de naturaleza; desarrollo comunitario; área protegida; Nevado de Toluca; México.

Nature tourism in protected areas of Mexico; a proposal for conservation, use and local development in the Nevado de Toluca

\section{ABSTRACT}

Nature Tourism in Protected Areas of Mexico is considered since the late twentieth century, as an instrument of socioeconomic development. Since this strategy is relatively

Recibido: 16 de abril de 2014

Devuelto para su revisión: 7 de julio de 2014

Aceptado: 8 de octubre de 2014

Facultad de Humanidades. Centro de Estudios Territoriales Iberoamericano. Universidad de Castilla la Mancha. Campus Universitario. Edificio Benjamín Palencia. 02071 ALBACETE (España). E-mail. jmsjasso@gmail. com, Francisco.Cebrian@uclm.es 
novel for Latin America,its implementation requires special and careful treatment. It is necessary to adhere to the principles of conservation and sustainable use. We analyze the Cacalomacán Rural Ecological Park, located within the Nevado de Toluca Volcano. It is an area of interest for the conservation of biodiversity, where nature tourism has become a tool for community development. The used methodology was the Weighted System Resource Inventory and Resources Evaluation.

Keywords: Nature tourism; community development; protected area; Nevado de Toluca; Mexico.

\section{LA IMPORTANCIA DEL TURISMO DE NATURALEZA Y SU RELACIÓN CON EL DESARROLLO LOCAL}

Las estrategias de desarrollo local suelen tener efectos diversos y multisectoriales ya que son resultado, en la mayoría de los casos, de la participación colegiada de diferentes agentes locales y externos. Generalmente traspasan los tradicionales planteamientos puramente económicos e incorporan perspectivas ambientalistas y sociales. Su objeto es impulsar el desarrollo endógeno, la auto-organización y el bienestar social. Significa un cambio en la mentalidad y en las maneras de visualizar y entender las representaciones del mundo, y se generan a partir de los recursos locales, de la formación de la población, de la conservación del ambiente, de la implicación de agentes sociales y de la presencia de proyectos macro y microregionales. En definitiva supone una reproducción a escala local de sistemas políticos, económicos, ambientales y culturales (Mínguez, 2008: 68-69).

El turismo de naturaleza, asociado al desarrollo local, puede entenderse como «un proceso reactivador de la economía y dinamizador de la sociedad, mediante el aprovechamiento eficiente de los recursos existentes en una zona determinada; capaz de estimular y diversificar la economía, generar empleo y mejorar la calidad de vida; siendo el resultado de un compromiso de solidaridad activa, que implica cambios en grupos e individuos» (Comité Económico y Social de las Comunidades Europeas, citado por González y García, 1998). En este proceso complejo, el territorio aparece como un recurso estratégico no deslocalizable, que está cargado de identidad personal y comunitaria (es su principal valor desde el punto de vista ambiental, económico y social, pero también en su dimensión paisajística y recreativo-turística). Si se logra impulsar el crecimiento en algunos ámbitos espaciales, sin romper sus lógicas internas y sin alterar excesivamente sus estructuras previas, se pueden obtener efectos positivos, con beneficios económicos, pero sobre todo con beneficios ambientales para la población local. Es en este contexto que centramos la atención en el Parque Ecológico Ejidal de Cacalomacán, un espacio concreto dentro del Nevado de Toluca. Aquí son los recursos naturales y paisajísticos los que actúan como motor de desarrollo local, de crecimiento económico y de generación de empleos alternativos a los tradicionales del medio rural. Con especial protagonismo aparece el turismo de naturaleza, con actividades como la recreación, la educación ambiental y la investigación científica. Hay por ello una relación, estrecha y creciente, entre las nuevas formas de turismo y el desarrollo local de las comunidades que habitan dentro de las áreas protegidas del país. 


\subsection{Del turismo de masas al turismo de naturaleza: contexto internacional}

Desde el origen del turismo hasta la fecha han existido una serie de factores económicos, sociales, tecnológicos y psicológicos que han sido responsables de su evolución y comportamiento. Destacan la mayor capacidad de gasto, la reducción del horario laboral, el incremento en el tiempo de ocio, la generalización de medios de transporte y comunicación, la facilidad de desplazamientos, la accesibilidad a la información o la necesidad de espacios de descanso y recreación. Algunos de ellos han derivado en una fuerte atención y atracción hacia la naturaleza y sus manifestaciones como elemento de uso y consumo (OMT, 2002). A mediados del siglo XX el éxito y expansión del turismo a nivel mundial llevó a la consolidación de un modelo democratizado, de masas. Dejaba flujos intensos y continuos de turistas en espacios y tiempos determinados, dominado en su mayoría por compañías transnacionales, en donde el impacto ambiental negativo, sobre todo en las zonas costeras, ha sido evidente, -para algunos espacios con daños irreversibles- (Boshet. Alt, 1998). El agotamiento y saturación de determinados destinos, ocasionado por el turismo masivo, ha derivado en la búsqueda de formas alternativas, diversificadas y de bajo impacto, especialmente en los espacios rurales, naturales y culturales, dando paso al turismo alternativo. Esta modalidad se caracteriza por las preferencias diferentes de los turistas, por el papel incuestionable de los nuevos sistemas de relación (internet especialmente), por la creciente conciencia ambiental, pero también porque las sociedades locales entienden que algunos de sus recursos territoriales tienen indudables atractivos turísticos.

Existe un amplio espectro terminológico de acepciones del turismo alternativo que centran su atención en el uso de espacios de amplia fragilidad ambiental y sociocultural. En ocasiones dejan enfoques imprecisos y confusos. Es el caso del turismo de naturaleza, turismo de aventura, turismo rural, turismo comunitario, turismo en espacios naturales protegidos, ecoturismo, agroturismo y turismo sostenible. La OMT parte de la idea de que el turismo alternativo tiene como «motivación principal la observación y apreciación de la naturaleza y de las culturas tradicionales» (OMT, 2002:16). Se trata de una modalidad basada en la actitud, conducta, compromiso y respeto (Dachary, 2002). Tiene también como finalidad poner en contacto al turista con las distintas actividades y costumbres que se realizan en comunidades locales, donde se puede participar en las tareas rurales, en educación y conciencia ambiental, consumiendo productos de los diferentes territorios, o participando en tradiciones religiosas o culturales (Daltabuit et Alt., 2000). Se incluye también el consumo de paisaje mediante la realización de actividades de bajo impacto ambiental, como senderismo, cicloturismo, observación e interpretación de la flora y fauna. Este proceso suele dejar beneficios (también hay perjuicios si no se desarrolla de manera organizada), ya que posibilita la creación de empleo, el arraigo de la población, la preservación del ambiente natural y patrimonio cultural, a la vez que promueve el desarrollo socioeconómico. El turismo alternativo rechaza todo tipo de características asociadas a otras modalidades de masas.«Su carácter es activo, no masivo» (SECTUR-México, 2007).

Pese al esfuerzo conceptualizador y regulador, es evidente que se ha abusado de términos como «sostenible» «ecológico» «alternativo»y «natural» desde diferentes ámbitos de la sociedad. Ejemplo son las políticas y campañas de «imagen verde» que practican algunas empresas y/o instituciones, que ocultan o banalizan las contradicciones y daños 
ocasionados al ambiente (Naredo, 2004). El cuestionado paradigma de la sostenibilidad, aplicado al turismo (Naredo, 1996), cobra carta de naturaleza hacia finales del siglo XX, con implicaciones directamente relacionadas con la planificación y la gestión turística (Ivars et Alt, 2001:6). Su uso está en correspondencia con dos procesos paralelos: por un lado la sobrecarga e impactos que algunos destinos consolidados experimentan; por otro la introducción del turismo en territorios de extrema fragilidad ambiental y social. Como resultado surge la idea del turismo sostenible, que se ha definido como «aquel que mantiene un equilibrio entre los intereses sociales, económicos y ecológicos y que debe integrar las actividades económicas y recreativas con el objetivo de la conservación de los valores naturales y culturales» (41 congreso de la Asociación Internacional de Expertos Científicos en Turismo, AIEST; en Pulido, 2005: 119). Han surgido definiciones apoyadas en las prioridades y necesidades de la oferta y la demanda a nivel mundial, en la preservación del ambiente y en la población local (Butler, 1991; Hunter, 1995; OMT, 1993). Lo cierto es que esta modalidad persigue el equilibrio ecológico, económico, cultural y social. Para lograrlo se han generado conceptos como el de capacidad de carga para instrumentalizar los límites de uso, o el de gestión turística sostenible, aplicada al ordenamiento y la planificación de los destinos.

Dado que la actividad turística depende de los recursos naturales, culturales y/o históricos de la zona; de la participación de la comunidad local; y de la propia gestión del turismo (Mollard y Pecqueur, 2001), se pone de manifiesto la urgente necesidad de articular estrategias reguladoras, a través de políticas públicas ambientales, para integrar el uso turístico en estas zonas, claves para la protección y preservación ambiental.

Esta reestructuración de pensamiento tiene como objetivo lograr un desarrollo turístico sostenible, definido por la Organización Mundial del Turismo como «aquella actividad que atiende a las necesidades de los turistas actuales y de las regiones receptoras y al mismo tiempo protege y fomenta las oportunidades para el futuro. Se concibe como una vía hacia la gestión de todos los recursos, de forma que puedan satisfacerse las necesidades económicas, sociales y estéticas, respetando al mismo tiempo la integridad cultural, los procesos ecológicos esenciales, la diversidad biológica y los sistemas que sostienen la vida» (OMT, 1995).

La presente investigación pretende poner en relación estos procesos de cambio, que son generales y se perciben de forma decidida en México, y sus efectos sobre un territorio de elevado valor geológico, ecológico y cultural, el Nevado de Toluca. Se ha organizado en varias partes, además de la introducción y las consideraciones finales: una primera dedicada a establecer el marco de referencia del turismo de naturaleza en México, otra a presentar los caracteres específicos del territorio objeto de atención, y una tercera de carácter propositivo, en la que se establecen estrategias de actuación para un espacio concreto (el Parque Ecológico Ejidal de Cacalomacán). Las hipótesis se fundamentan en la importancia de promover entre las comunidades, ubicadas dentro de las áreas protegidas del país, proyectos de desarrollo local basados en la preservación de los recursos paisajísticos, ambientales y culturales, con actividades compatibles con la conservación de la biodiversidad y el aprovechamiento sostenible. También en el hecho de que en el Nevado de Toluca es posible el desarrollo de proyectos turísticos de bajo impacto ambiental, y con ello se abre una puerta al desarrollo local a partir del impulso regulado, ordenado y 
controlado de estas actividades. Los objetivos del trabajo se han centrado en hacer un discurso propositivo, dirigido a impulsar un desarrollo armónico del turismo con los valores sociales y ambientales de este territorio.

\subsection{El turismo de naturaleza en México: beneficios y costes}

La Secretaría de Turismo de México (2004), intentando equilibrar la planificación y el desarrollo del turismo en territorios de elevada fragilidad con las exigencias, gustos y preferencias de quienes desean consumirlos, ha buscado unificar y estandarizar los criterios del turismo alternativo basándose en el punto de vista de quien compra y efectúa el viaje. De ahí surge el concepto de turismo de naturaleza, definido por este organismo como«los viajes que tienen como fin realizar actividades recreativas en contacto directo con la naturaleza y las expresiones culturales que la envuelven, con una actitud y compromiso de conocer, respetar, disfrutar y participar en la conservación de los recursos naturales y culturales».

A partir del concepto de turismo de naturaleza se han establecido tres categorías, propias del ámbito mexicano, que incorporan diferentes modalidades: ecoturismo, turismo rural y turismo de aventura. Todas ellas se permiten en áreas protegidas bajo las directrices de la Ley General del Equilibrio Ecológico y Protección al Ambiente y los reglamentos en materia de Áreas Naturales Protegidas.

- El ecoturismo se define como los viajes que tienen como fin realizar actividades recreativas de observación y conocimiento de la naturaleza (senderismo interpretativo, safari fotográfico y avistamientos de flora o fauna) (en la Europa mediterránea se aplica al turismo en espacios protegidos).

- El turismo rural se refiere a los viajes que tienen como fin realizar actividades de convivencia e interacción con una comunidad rural, en todas aquellas expresiones sociales, culturales y productivas (agroturismo, fotografía rural, talleres artesanales o gastronómicos, preparación y uso medicinal) (en Europa se aplica a actividades desarrolladas en entornos rurales).

- El turismo de aventura, se define como los viajes que tienen como fin realizar actividades recreativas, asociadas a desafíos impuestos por la naturaleza (caminata, escalada, rappel, ciclismo de montaña, alta montaña, descenso de ríos, buceo, espeleología, vuelo en globo o en ala delta).

El turismo de naturaleza, en cualquiera de sus variantes, constituye una importante fuente de empleo e ingresos económicos por su capacidad de desarrollo cuando se planifica y gestiona adecuadamente (Crosby, 1993; Cebrián, 2008). La Comisión para la Cooperación Ambiental (CCA, 2000) apunta que entre el $40 \%$ y el $60 \%$ de los viajes turísticos internacionales son de personas que aprecian la naturaleza. Wearing y Neil (1999) afirmaban, a finales del siglo pasado, que los viajes de naturaleza eran los de crecimiento más rápido, por encima de otras modalidades (se calculaba que crecían entre $10 \%$ y $30 \%$ al año a finales del siglo XX). No obstante esta actividad no está exenta de posiciones encontradas (entre defensores y detractores). Para unos sirve como una opción de desa- 
rrollo de la población local y una forma de contribuir a la conservación de la naturaleza y a la educación ambiental. Para otros en cambio supone un riesgo, puesto que conlleva el acercamiento de turistas a zonas naturales, culturales y tradiciones, con las consecuencias derivadas de sus impactos. A partir de las ideas de Crosby (1993) y Cebrián (2008), se han identificado los siguientes beneficios y costes que genera el turismo de naturaleza (Cuadro 1).

\section{Cuadro 1}

BENEFICIOS Y COSTES QUE GENERA EL TURISMO DE NATURALEZA

\begin{tabular}{|c|c|}
\hline BENEFICIOS & COSTES \\
\hline \multicolumn{2}{|c|}{ ECONÓMICOS } \\
\hline Incremento de ingresos locales. & $\begin{array}{l}\text { Creación de infraestructura o servicios no } \\
\text { compatibles con la zona. }\end{array}$ \\
\hline servicios. & Peligro de monoactividad. \\
\hline $\begin{array}{l}\text { Desarrollo de productos locales y artesanía. } \\
\text { Oportunidades laborales. }\end{array}$ & $\begin{array}{l}\text { Precariedad laboral en los nuevos puestos de } \\
\text { trabajo. }\end{array}$ \\
\hline $\begin{array}{l}\text { Reequilibrio de la población local al reducir } \\
\text { migraciones e incrementar el retorno. }\end{array}$ & $\begin{array}{l}\text { Introducción de inversiones ajenas a la loca- } \\
\text { lidad. }\end{array}$ \\
\hline Mejora de infraestructuras. & $\begin{array}{l}\text { Escasez o ausencia de reparto de las rentas } \\
\text { entre la comunidad. }\end{array}$ \\
\hline \multicolumn{2}{|c|}{ AMBIENTALES } \\
\hline $\begin{array}{l}\text { Mantenimiento, conservación y mejora de los } \\
\text { espacios naturales. }\end{array}$ & $\begin{array}{l}\text { Perturbación de la biodiversidad por excesiva } \\
\text { afluencia de visitantes. }\end{array}$ \\
\hline $\begin{array}{l}\text { Concienciación local sobre el patrimonio, } \\
\text { que permite la revitalización de los recursos } \\
\text { naturales. }\end{array}$ & $\begin{array}{l}\text { Alteración de los ecosistemas. } \\
\text { Sobrexplotación de los recursos naturales. }\end{array}$ \\
\hline Sensibilización ambiental de los turistas. & (agua, aire, visual, auditiva). \\
\hline $\begin{array}{l}\text { Mantenimiento de la actividad agrícola or- } \\
\text { gánica y de los paisajes agropecuarios bien } \\
\text { manejados. }\end{array}$ & \\
\hline \multicolumn{2}{|c|}{ SOCIO-CULTURALES } \\
\hline $\begin{array}{l}\text { Recuperación y revitalización de la cultura } \\
\text { local. }\end{array}$ & $\begin{array}{l}\text { Conflicto comunidad local-visitante, expresa- } \\
\text { do en mayor competitividad por los servicios }\end{array}$ \\
\hline Consolidación de la identidad local. & y otros recursos. \\
\hline $\begin{array}{l}\text { Intercambios culturales y preservación de las } \\
\text { costumbres y tradiciones. }\end{array}$ & $\begin{array}{l}\text { Alteración y cambio en las tradiciones locales } \\
\text { y culturales. }\end{array}$ \\
\hline \multirow{2}{*}{$\begin{array}{l}\text { Aumento del interés de la comunidad por las } \\
\text { actividades turísticas y apoyo para las peque- } \\
\text { ñas empresas locales. }\end{array}$} & $\begin{array}{l}\text { Alteración del equilibrio social de la locali- } \\
\text { dad. }\end{array}$ \\
\hline & $\begin{array}{l}\text { Usurpación de identidad y marginación de la } \\
\text { comunidad local por parte los visitantes. }\end{array}$ \\
\hline
\end{tabular}

Fuente: Crosby, 1993; Cebrián., 2008. 


\section{EVOLUCIÓN E IMPLANTACIÓN DEL TURISMO DE NATURALEZA EN ÁREAS PROTEGIDAS DE MÉXICO}

Una de las estrategias más importantes a nivel mundial para lograr la conservación de la biodiversidad ha sido el establecimiento de Áreas Protegidas (AP), que en México difiere respecto a otros países. Se debe a que en el momento histórico en que se decretaron la mayoría de los Parques Nacionales - primeras áreas con reconocimiento internacional (1934-1940) - la tenencia de la tierra ya ostentaba regímenes de propiedad ejidal ${ }^{1}$, comunal $^{2}$ y privada, con fines de desarrollo económico y no de conservación, lo que ha ocasionado incongruencias e inoperancia en el manejo de estos espacios hasta la época actual (Sierra, 2013).

México define a las Áreas Naturales Protegidas (ANP) ${ }^{3}$ como «zonas del territorio nacional y aquellas sobre las que la nación ejerce soberanía y jurisdicción, en la que los ambientes originales no han sido significativamente alterados por la actividad del ser humano, o que requieren ser preservadas o restauradas. Los propietarios, poseedores o titulares de otros derechos sobre tierras, aguas y bosques comprendidos dentro de las áreas naturales protegidas deberán sujetarse a las modalidades que de conformidad con la presente Ley establezcan los decretos por los que se constituyan dichas áreas, así como las demás previsiones contenidas en el programa de manejo y en los programas de ordenamiento ecológico que correspondan»(LGEEPA, 2013). Actualmente, México cuenta con 176 ANP que en suma representan el $12.93 \%$ de la superficie total del país (CONANP4 ${ }^{4}$ 2013).

Algunos datos de la Food and Agriculture Organization (FAO, 2008) resaltan la importancia de países como Brasil, Colombia, Ecuador, México, Perú y Venezuela, quienes se encuentran en la lista de los 17 países con mayor biodiversidad a nivel mundial, no solo por la riqueza de flora y fauna, sino también por la riqueza cultural existente. México en el año 2000 contaba con una población de 7.618 .990 habitantes viviendo dentro de las ANP, que en suma representaban el 7,9\% de la población total (Sierra, 2013). Por ello,es indispensable tener presente la importancia en términos cuantitativos y culturales de las comunidades en proyectos productivos y de desarrollo, articulados sobre los principios del desarrollo local y la conservación de los recursos naturales y culturales.

1 Propiedad Ejidal: Son las tierras, bosques y aguas concedidas mediante resolución presidencial, sentencia del Tribunal Superior Agrario o mediante la aportación de terrenos para la constitución de nuevos ejidos, con las modalidades y regulaciones que prevé la Ley Agraria. Los bienes ejidales son susceptibles de uso y aprovechamiento de manera individualizada, de acuerdo con la propia resolución o sentencia, o de conformidad a las decisiones tomadas por la asamblea del núcleo.

2 Propiedad Comunal: Se llama así al conjunto de tierras, bosques y aguas, patrimonio de los núcleos de población, que de hecho o por derecho guarda el estado comunal. Este régimen de propiedad se caracteriza porque la titularidad de dichos bienes corresponde a la comunidad; su aprovechamiento es derecho de todos los miembros de manera colectiva, a menos que la propia asamblea decida asignar porciones de terreno en forma individual.

3 En México se utiliza el término Área Natural Protegida, es el homólogo de Área Protegida. Ley General del Equilibrio Ecológico y Protección al Ambiente (Artículo 44, LGEEPA).

4 Comisión Nacional de Áreas Naturales Protegidas (CONANP). 
Es a partir de la Conferencia Mundial de Turismo (celebrada en Lanzarote, 1995) cuando México considera, por primera vez, al turismo en Áreas Naturales Protegidas como un instrumento de política pública capaz de promover el desarrollo socioeconómico de las comunidades y salvaguardar los recursos naturales (OMT, 1995). El estudio Estratégico de Viabilidad del Segmento de Ecoturismo en México (2001) estimaba que el valor anual del mercado formal de actividades turísticas vinculadas con la naturaleza era superior a los 750 millones de pesos (2001), de los cuales 64,2\% se atribuía a visitantes extranjeros y el $35,8 \%$ a nacionales. Ante el incremento de la actividad turística vinculada con la naturaleza se formuló, en el año 2001, el Programa Intersecretarial de Turismo de Naturaleza, que fue ratificado con la firma del Convenio General de Colaboración Interinstitucional para el Desarrollo del Turismo de Naturaleza en México.

Ante la falta de información actualizada sobre el turismo de naturaleza, la Secretaria de Turismo (SECTUR) elaboró en 2006 el primer inventario nacional de empresas y proyectos ecoturísticos. Como balance dejaba un total de 1.239 empresas y/o proyectos orientados a ofrecer servicios para el turismo de naturaleza. El $70 \%$ de ellas eran empresas que se encuentran en operación y recibiendo visitantes y el 30\%correspondía a iniciativas en proceso de desarrollo. El $74 \%$ de ellas son de tipo comunitario o social, integradas principalmente por grupos rurales o indígenas y el $26 \%$ por empresas privadas. Con esta información SECTUR elaboró el Plan Estratégico de Turismo de Naturaleza 2006-2015, en donde se establecen las disposiciones legales y las estrategias planteadas en la legislación vigente, así como otras Estrategias y Declaraciones relacionadas con el turismo.

Aunque los esfuerzos descritos en los párrafos anteriores suponen el inicio del turismo de naturaleza en México, algunos autores consideran que debido a la falta de información, capacitación, normatividad, continuidad, así como de la integración y relación entre los habitantes y el territorio,el turismo de naturaleza, aun no se ha convertido en un detonante para el desarrollo sostenible a nivel nacional (Ceballos-Lascurain, 1994; Skrei, 1998, Nieva, 2005 y Mader, 2006). Pese a ello algunos territorios concretos, como es el caso del ejido de Cacalomacán han impulsado alianzas estratégicas con instituciones académicas y organizaciones gubernamentales y no gubernamentales, que han aportado conocimiento, recursos humanos y económicos para el desarrollo y fortalecimiento turístico del Parque Ecológico Ejidal de Cacalomacán.

\subsection{El Nevado de Toluca: un ecosistema vulnerable con usos y aprovechamientos turísticos}

El Nevado de Toluca, fue decretado como Área Natural Protegida con la categoría de Parque Nacional el 25 de enero de 1936 (DOF, 1936) y el pasado 01 de octubre de 2013, fue recategorizado a Área de Protección de Flora y Fauna Nevado de Toluca (CONANP, 2013, DOF, 2013). Es un volcán activo en estado de quiescencia (Capra et Alt, 2008), con lagos permanentes en el cráter. Está considerado como una Región Terrestre Prioritaria (RTP-109) debido a la biodiversidad, endemismos, al alto valor 
biológico y paisajístico $\left(\mathrm{CONABIO}^{5}, 2010\right)$. Su rasgo distintivo es el volcán Xinantécatl que se eleva hasta los 4660 metros sobre el nivel del mar, posicionándose como la cuarta montaña más alta del país, en donde nacen dos cuencas hidrológicas (LermaChapala-Santiago y Balsas). Su peculiar estructura geográfica la convierte en una zona de recarga de agua que abastece las necesidades de millones de habitantes del valle de Toluca y parte de la Zona Metropolitana de la ciudad de México (Figura 1). Según los datos aportados por el Instituto Nacional de Estadística y Geografía (INEGI, 2010), la población residente en el área es de 5.297 habitantes, mismos que han hecho uso de los recursos naturales desde antes del decreto de creación como Parque Nacional, pero también los que han generado una cultura diferenciada con tradiciones propias. Es por tanto un ícono de la geografía mexicana, que integra, alrededor de la majestuosa montaña, naturaleza, paisaje, cultura, tradición, religión y arte (Ávila et Alt., 2012). El atractivo de estos recursos territoriales turísticos ha impulsado su papel como destino emergente, aunque surgido de forma no planificada e improvisada al amparo de la singularidad del parque y sus valores.

Es importante destacar que en el decreto de 1936, que declaraba al Nevado de Toluca como Parque Nacional, ya se consideraba al desarrollo del turismo como actividad productiva alterna dentro del área protegida («que la misma belleza natural de esa montaña, su flora y fauna forman un atractivo poderoso para el desarrollo del turismo...»-DOF, 1936-). La propuesta de desarrollo turístico en el Parque Ecológico Ejidal de Cacalomacán (PEEC) plasmada en el presente documento, se realizó bajo la normativa de Parque Nacional. La modificación de categoría a Área de Protección de Flora y Fauna Nevado de Toluca, no afecta las acciones y actividades contempladas para el PEEC, ya que en ambos decretos se considera el desarrollo del turismo de bajo impacto ambiental como una actividad permitida y compatible con la conservación y aprovechamiento de los recursos naturales (DOF, 1936; DOF, 2013).

Osorio et Alt. (2011) identificaron tres tipologías de visitantes en el Nevado de Toluca (NT): el visitante masivo de convivencia, el visitante selectivo de áreas naturales y el visitante de prácticas deportivas. En su mayoría son jóvenes que vienen al parque en compañía de amigos o familiares. La motivación principal es recorrer el cráter del volcán y sus lagos. Los turistas desean -y así lo manifiestan- un paisaje más limpio y mejor conservado, aunque su comportamiento revela el predominio de hábitos tradicionales de consumo recreativo sobre un paisaje natural. Desafortunadamente el perfil dominante del visitante del NT mantiene el mismo comportamiento masivo y depredador típico de los años ochenta, que ha ocasionado impactos ambientales severos (erosión, contaminación del agua, incendios forestales, incremento de residuos sólidos urbanos, grafiti en rocas y árboles, apertura de caminos y senderos sin control, pérdida del paisaje visual por construcciones ajenas al entorno, contaminación sonora y falta control de la capacidad de carga de los espacios destinados a la actividad turística), que se intensifican en la época invernal, sobre todo en tiempo de nieve o coincidiendo con la programación de eventos masivos (Sierra, 2013).

5 Comisión Nacional para el Conocimiento y Uso de la Biodiversidad. 


\section{Figura 1 \\ LOCALIZACIÓN DEL NEVADO DE TOLUCA}

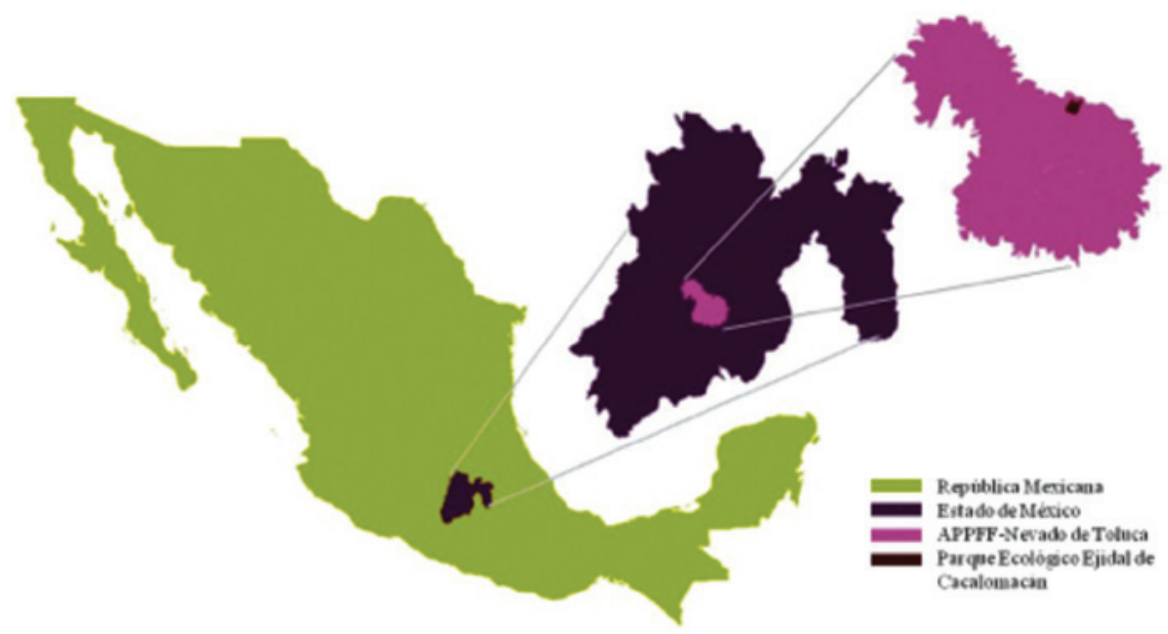

Con la finalidad de organizar el proceso de configuración de un sistema turístico local se ha puesto en marcha un proyecto comunitario, que depende de la disponibilidad, organización, participación y capacitación de la comunidad. Se ha tomado como estudio de caso al Parque Ecológico Ejidal de Cacalomacán, sobre el que se ha propuesto un modelo de desarrollo turístico de naturaleza, apoyado en una metodología que integra información del medio físico, biológico y social; un inventario y evaluación de los recursos turísticos; la identificación del tipo de oferta y demanda; y el ordenamiento y planeación de las actividades a realizar en la zona. Sobre este espacio se ha realizado una propuesta de actuación que persigue integrar recursos territoriales, con implicación social y posibilidades de desarrollo turístico.

\section{PARQUE ECOLÓGICO EJIDAL DE CACALOMACÁN}

El Parque Ecológico Ejidal de Cacalomacán (PEEC) se ubica dentro del Nevado de Toluca, entre las coordenadas extremas UTM: 421665mE y $2124155 \mathrm{mN}$ al Norte, $423171 \mathrm{mE}$ y $2123973 \mathrm{mN}$ al Noreste, $422235 \mathrm{mE}$ y $2122130 \mathrm{mN}$ al Sur y $420885 \mathrm{mE}$ y $2122612 \mathrm{mN}$ al Oeste, en un gradiente altitudinal de 2.800 a $3.247 \mathrm{msnm}$. Forma parte de las tierras de uso común del ejido de Cacalomacán ${ }^{6}$. Tiene una superficie de 240 hectáreas. El clima es templado semifrío con lluvias en verano, y una temperatura media anual que

6 El Artículo 73 de la Ley Agraria Nacional, establece que las tierras de uso común ejidales, constituyen el sustento económico de la vida en comunidad del ejido y están conformadas por aquellas tierras que no hubieren sido reservadas por la asamblea para el asentamiento del núcleo de población, ni sean tierras parceladas. 
oscila entre 4 y $12{ }^{\circ} \mathrm{C}$. La temperatura máxima se da en los meses de abril y mayo (12 y $13^{\circ} \mathrm{C}$ ) y la mínima entre enero y diciembre $\left(8\right.$ y $\left.9^{\circ} \mathrm{C}\right)$, con una precipitación media anual de $1200 \mathrm{~mm}$ (García, 1981). Se asienta sobre un cono volcánico producto de la última erupción del Volcán Nevado de Toluca. Presenta un gradiente altitudinal que oscila entre los 2.900 a $3.246 \mathrm{msnm}$, con pendientes que alcanzan en algunos sectores $\operatorname{los} 45^{\circ}$. El $11 \%$ de la superficie total del cono aún conserva sus características originales y el $89 \%$ se subdivide en cimas, laderas y valles erosivo-acumulativos de primer y segundo orden. El tipo de suelo predominante es andosol y la hidrología está representada por corrientes de agua intermitentes. El tipo de vegetación corresponde a un bosque secundario de coníferas (bosque de Cupressus-Pinus, Pinus-Cupressus, vegetación secundaria, riparia y pastizal) (Sánchez-Jasso, 2012), producto de la destrucción total o parcial de la vegetación original, realizada por el cambio de uso de suelo de forestal a agropecuario en 1920, y la posterior reforestación en la década de los ochenta.

El PEEC inició su historia en el año 2003, cuando el ejido de Cacalomacán, en coordinación con el Gobierno Municipal de Toluca, impulsó la creación del Parque (sin que se hayan establecido normativas reguladoras de uso, con el consecuente deterioro ambiental). En 2009, como resultado de un Acuerdo Operativo de Colaboración con la Universidad Autónoma del Estado de México, se realizó el primer estudio sobre la diversidad de vertebrados presentes en la zona, el cual ha sentado las bases para desarrollar la estrategia de conservación y manejo del parque. Los resultados apuntan que el PEEC, con sólo el $0,42 \%$ de la superficie total del NT, acumula el $11,1 \%$ de la riqueza de vertebrados del Estado de México. Se tienen registros de 85 especies de vertebrados, de los cuales 24 son endémicas de México, 14 se encuentran en alguna categoría de riesgo según la NOM059-SEMARNAT, 2010 y 3 están en la lista roja de la UICN (Sánchez-Jasso et Alt., 2013). Estos hechos ponen de relieve la importancia de este espacio como zona para la conservación de la biodiversidad y la urgente necesidad de establecer una estrategia de manejo, aprovechamiento y desarrollo local congruente con la conservación del territorio y el turismo sostenible.

\subsection{Inventario y evaluación de los recursos turísticos}

Para conocer el estado actual y potencial de los recursos turísticos, se ha empleado el Sistema Ponderado de Inventario y Evaluación de Recursos (S.P.I.E.R) (Ávila, 2008). Este método permite identificar y evaluar las características intrínsecas e individuales de cada recurso (grado de conservación, valor cultural, valor ambiental, fragilidad y dificultad de uso para asegurar o mejorar la conservación, singularidad, atractivo y accesibilidad física, legal y estacional), así como el potencial temático, de conectividad y de inversión necesaria para desarrollar la actividad (Cuadro 2). En la ficha de diagnóstico se reflejan las potencialidades para introducir un turismo de naturaleza compatible con la conservación de los recursos naturales, la interpretación y educación ambiental en el PEEC (Cuadro 3). 


\section{Cuadro 2 \\ RESUMEN DE LA EVALUACIÓN DE LOS RECURSOS DEL PARQUE ECOLÓGICO EJIDAL DE CACALOMACÁN}

\begin{tabular}{|c|c|c|c|c|c|c|}
\hline \multirow[b]{2}{*}{ No } & \multirow{2}{*}{$\begin{array}{l}\text { Nombre del } \\
\text { Recurso }\end{array}$} & \multirow[b]{2}{*}{ Tipo de recurso } & \multicolumn{3}{|c|}{ Valoración } & \multirow{2}{*}{$\begin{array}{l}\text { Pondera- } \\
\text { ción }\end{array}$} \\
\hline & & & $\begin{array}{c}\text { Intrínseca } \\
(25 \%)\end{array}$ & $\begin{array}{c}\text { Turística } \\
(35 \%)\end{array}$ & $\begin{array}{c}\text { Temática } \\
(40 \%)\end{array}$ & \\
\hline \multicolumn{7}{|c|}{ RECURSOS BÁSICOS Y REALES } \\
\hline 1 & $\begin{array}{l}\text { Área Natural } \\
\text { Protegida } \\
\text { (recursos } \\
\text { integrados) }\end{array}$ & Natural/social & 2.45 & 3.6 & 3.6 & 9.65 \\
\hline 2 & Tierra Ejidal & Social/cultural & 1.75 & 3.2 & 3.6 & 8.55 \\
\hline 3 & Paisaje & Natural/vegetación & 1.75 & 2.45 & 3.6 & 7.8 \\
\hline 4 & $\begin{array}{l}\text { Cono volcá- } \\
\text { nico }\end{array}$ & Natural/geológico & 1.25 & 2.45 & 3.6 & 7.3 \\
\hline \multicolumn{7}{|c|}{ RECURSOS COMPLEMENTARIOS Y POTENCIALES } \\
\hline 5 & $\begin{array}{l}\text { Flora y fauna } \\
\text { silvestre (esta- } \\
\text { cional) }\end{array}$ & $\begin{array}{l}\text { Natural/biodiversidad/ } \\
\text { educación ambiental }\end{array}$ & 2.45 & 3.2 & 3.2 & 9.25 \\
\hline 6 & $\begin{array}{l}\text { Micología } \\
\text { (estacional) }\end{array}$ & $\begin{array}{l}\text { Natural/biodiversidad/ } \\
\text { educación ambiental }\end{array}$ & 2.45 & 3.2 & 3.2 & 9.25 \\
\hline 7 & $\begin{array}{l}\text { Avistamiento } \\
\text { de estrellas }\end{array}$ & Natural/recreación & 1.75 & 2.45 & 3.2 & 7.4 \\
\hline 8 & Paisaje & Natural/arte & 2.45 & 3.2 & 3.2 & 9.25 \\
\hline 9 & Zona forestal & $\begin{array}{l}\text { Natural/educación am- } \\
\text { biental }\end{array}$ & 2.45 & 2.45 & 3.6 & 8.5 \\
\hline 10 & Gastronomía & $\begin{array}{l}\text { Natural/agricultura or- } \\
\text { gánica }\end{array}$ & 1.75 & 2.45 & 3.2 & 7.4 \\
\hline 11 & Cultura local & Natural/social & 1.75 & 2.45 & 3.6 & 7.8 \\
\hline 12 & $\begin{array}{l}\text { Estación bio- } \\
\text { lógica/ } \\
\text { UMA }\end{array}$ & $\begin{array}{l}\text { Natural/investigación/ } \\
\text { Conservación }\end{array}$ & 2.45 & 3.6 & 3.6 & 9.65 \\
\hline
\end{tabular}

*UMA: Unidad de Manejo para la Conservación de la Vida Silvestre.

Fuente: elaboración propia. 


\section{Cuadro 3 \\ FICHA DE DIAGNÓSTICO INTEGRADO DEL INVENTARIO DEL PARQUE ECOLÓGICO EJIDAL DE CACALOMACÁN}

\begin{tabular}{|c|c|}
\hline RECURSO & EVALUACIÓN \\
\hline \multicolumn{2}{|r|}{ CARACTERÍSTICAS INTRÍNSECAS DEL RECURSO } \\
\hline Valor cultural/ambiental & Muy alto. Producto integrado único en el Nevado de Toluca (NT) y a nivel regional. \\
\hline Singularidad/atractivo & $\begin{array}{l}\text { Muy alta.Espacio hecho a base de ecotecnias,que lo convierte en privilegiado paraeducación, investigación e } \\
\text { interpretación ambiental. Además se pueden introducir actividades recreativas y de ocio }\end{array}$ \\
\hline Grado de conservación & $\begin{array}{l}\text { Medio. Se observan huellas de deterioro ambiental debido a la falta de regulación y una estructura adminis- } \\
\text { trativa y de operación única del PEEC. }\end{array}$ \\
\hline $\begin{array}{l}\text { Nivel jerárquico actual de } \\
\text { la oferta del patrimonio y } \\
\text { recursos }\end{array}$ & $\begin{array}{l}\text { Bajo. Se requiere del fortalecimiento del capital social, promoción y difusión, así como estrategias de recu- } \\
\text { peración, puesta en valor de recursos, creación de productos turísticos y de marketing adecuadas. }\end{array}$ \\
\hline \multicolumn{2}{|r|}{ CARACTERÍSTICAS INDIVIDUALES DEL RECURSO TURÍSTICO } \\
\hline $\begin{array}{l}\text { Conectividad real con } \\
\text { otros destinos y productos }\end{array}$ & $\begin{array}{l}\text { Baja. Dentro del NT no existen redes enfocadas al turismo de naturaleza con otros destinos. No existen } \\
\text { centros de interpretación ni de información respecto a la oferta. }\end{array}$ \\
\hline $\begin{array}{l}\text { Conectividad potencial } \\
\text { con otros destinos y pro- } \\
\text { ductos }\end{array}$ & $\begin{array}{l}\text { Muy alta. El Parque Ecológico Ejidal de Cacalomacán (PEEC) puede convertirse en el eje de una nueva } \\
\text { valoración del patrimonio natural y cultural del NT. }\end{array}$ \\
\hline $\begin{array}{l}\text { Interés para la diversifica- } \\
\text { ción del turismo regional }\end{array}$ & $\begin{array}{l}\text { Muy alto. Dentro de las Áreas Naturales Protegidas del Estado de México es aún incipiente la diversificación } \\
\text { del mercado turístico, sobre todo del turismo de naturaleza. }\end{array}$ \\
\hline $\begin{array}{l}\text { Dotación de servicios para } \\
\text { su uso turístico }\end{array}$ & $\begin{array}{l}\text { Medio. Es necesario rehabilitar y mejorar los servicios, así como capacitar a la comunidad para brindar una } \\
\text { adecuada atención al cliente. }\end{array}$ \\
\hline $\begin{array}{l}\text { Posible desarrollo temá- } \\
\text { tico y potencialidad de } \\
\text { interpretación }\end{array}$ & $\begin{array}{l}\text { Muy alto. Existen condiciones para establecer programas de educación e interpretación ambiental, avista- } \\
\text { miento de hongos, flora y fauna, proyectos de investigación científica y conservación de los recursos natu- } \\
\text { rales. }\end{array}$ \\
\hline Resistencia al impacto & $\begin{array}{l}\text { Media. Es necesario conocer la capacidad de carga de cada uno de los lugares de acceso público, elaborar } \\
\text { reglamentos de uso y programas de señalización. }\end{array}$ \\
\hline Fidelización potencial & Alta, sobre todo en momentos puntuales y ligada a eventos. \\
\hline \multicolumn{2}{|r|}{ POTENCIALIDAD PARA APORTAR PRODUCTOS COMPLEJOS Y DIVERSIFICADOS } \\
\hline $\begin{array}{l}\text { Inversión requerida en } \\
\text { conservación y recupe- } \\
\text { ración }\end{array}$ & Muy alta. Es necesario el mantenimiento y recuperación de amplios sectores. \\
\hline $\begin{array}{l}\text { Inversión requerida para } \\
\text { su puesta en valor turístico }\end{array}$ & $\begin{array}{l}\text { Alta. Es necesario realizar actuaciones en conjunto entre instituciones y organizaciones para recuperar y } \\
\text { poner en valor los recursos turísticos. }\end{array}$ \\
\hline $\begin{array}{l}\text { Grado de interés de la pro- } \\
\text { puesta }\end{array}$ & Muy alto, ante la ausencia de los productos turísticos similares y la oferta innovadora que se propone. \\
\hline Necesidades & Pasar de un producto poco organizado a otro estructurado. Poner en valor recursos potenciales. \\
\hline $\begin{array}{l}\text { Consecución de una ges- } \\
\text { tión viable y rentable del } \\
\text { patrimonio y los recursos }\end{array}$ & $\begin{array}{l}\text { Factible, ya que se cuenta con el capital social y el apoyo de instituciones académicas,gubernamentales y } \\
\text { no gubernamentales. }\end{array}$ \\
\hline
\end{tabular}

Fuente: elaboración propia. 


\subsection{Análisis de la oferta y la demanda}

De acuerdo con la evaluación de los recursos turísticos, el PEEC ofrece a los visitantes recursos básicos y reales vinculados al paisaje y la diversidad biológica; cuenta también con potencialidades para las prácticas de deportes, excelente ubicación, fácil accesibilidad y una comunidad local dispuesta a recibir turistas, con una cultura propia que se ha convertido en atractiva. Junto a los recursos básicos y reales aparecen otros a los que se ha dado la consideración de complementarios y potenciales, que están asociados al avistamiento estacional de flora y fauna, a la observación de estrellas, a la micología, a la agricultura orgánica, al establecimiento de una estación biológica para el monitoreo e investigación científica, a la creación de una Unidad de Manejo para la Conservación de la Vida Silvestre (UMA), a la educación e interpretación ambiental (en especial las especies bandera), así como al posible desarrollo de actividades al aire libre (yoga, paisajismo y fotografía).Se añade a todo ello, que el espacio cuenta con una zona dotada de servicios y varios espacios acondicionados para campismo, senderismo y ciclismo.

Para identificar el perfil del visitante, se aplicó un cuestionario de 15 preguntas a 70 usuarios, en un periodo de 5 semanas. Los resultados de la encuesta dejaban un $40 \%$ de jóvenes (de 21 a 30 años); un 56\% de varones; y un 19\% niños menores de 10 años. El $70 \%$ de los que visitaron el parque lo hicieron en familia; un $22 \%$ con amigos, el $6 \%$ con compañeros de trabajo y $2 \%$ solos. El $84 \%$ manifestó que la motivación principal era la recreación y el descanso, el $10 \%$ el entrenamiento deportivo y el $6 \%$ el contacto con la naturaleza. El 94\% procedía del Estado de México y el resto de la Ciudad de México (Distrito Federal); el ingreso mensual del $42 \%$ de los encuestados oscilaba entre 5 y 10 mil pesos (280 a 560 Euros); el 68\% viajó en automóvil; el 62\% permaneció entre 5 y 8 horas y sólo el $18 \%$ pernoctó en las instalaciones. Las principales actividades que realizaron fueron ciclismo (48\%); días de campo (18\%); campismo (16\%); fotografía (8\%), senderismo (6\%) e investigación (4\%). Estos datos han ayudado a entender, a falta de otros estadísticamente más representativos, la tipología y preferencias de los turistas, así como las percepciones del espacio y los servicios actuales y potenciales del sistema turístico.

Dado que, los destinos turísticos de naturaleza no están preparados para un turismo masivo, desde el punto de vista de la imagen publicitaria; es frecuente el uso de especies bandera en las estrategias de promoción, conservación o divulgación de las características del espacio y sus valores. Las especies bandera son aquellas que gozan de cierta simpatía o aquellas que deben ser revalorizadas por la sociedad y gracias a ellas es posible elaborar programas de educación e interpretación ambiental que promuevan y generen vínculos entre la sociedad y la naturaleza (Gilbert, 1989 en García, 2008). Se convierten por tanto en recursos turísticos potenciales. Para identificar a las especies bandera del PEEC, se aplicó a los 70 encuestados un cuestionario para conocer las sensaciones y emociones (alegría, ternura, asombro, admiración, miedo, asco o indiferencia) que les provocaban las 85 especies registradas. De acuerdo con los resultados obtenidos, se identificaron un total de 25 especies bandera ${ }^{7}$ ( 2 anfibios, 3 reptiles, 16 aves y 4 mamíferos).

7 Anfibios: Pseudoeuryceabellii (salamandra), Hylaplicata (rana arborícola). Reptiles: Barisialmbricata (falso escorpión), Thamnophisscalaris (culebra),Storeriastorerioides (culebra), Crotalustriseriatus (víbora de cascabel). 
Las aves fueron el grupo más representativo, ya que al $98 \%$ de los encuestados les provoca sensaciones de alegría, ternura y asombro (les parecen «bonitas»), en especialMicrathenewhitneyi (búho elfo), Aegoliusacadicus (mochuelo afilador), Corvuscorax (cuervo), Cardelina ruber (chipe rojo), Hylocharisleucotis (colibrí) y Picoidesscalaris (carpintero mexicano). De las 16 especies 9 son migratorias. El grupo de los mamíferos obtuvo una valoración positiva en un $40 \%$ de los casos, con respuestas que apuntaron hacia las sensaciones de asombro, admiración y ternura. Mientras que para el $60 \%$ de los encuestados, el tlacuache -Didelphis virginiana- y el ratón de campo-Neotomodonalstoniprovoca miedo o asco (este último es endémico de las montañas altas de México).

Los anfibios y reptiles fueron los menos favorecidos en el proceso de identificación de preferencias, ya que solo despertó el interés en el $15 \%$ de los casos. Las sensaciones que provocan son miedo, asco, duda e indiferencia. Las cinco especies identificadas han sido castigadas socialmente por la creencia de que son venenosas (sólo la víbora de cascabel -Crotalustriseriatus- es venenosa, mientras que el resto son inofensivas), lo que las ha llevado al desprecio y maltrato social. Estas cinco especies son endémicas de México:la Pseudoeuryceabellii (salamandra) está catalogada como amenazada según la NOM-059-SEMARNAT, 2010 y como vulnerable en la lista roja de la UICN, mientras que Thamnophisscalaris(culebra) y Barisiaimbricata (Falso escorpión) se encuentran amenazadas y en protección especial respectivamente según la NOM-059-SEMARNAT, 2010.

A través del uso de las especies banderase puede generar una corriente de respeto y entendimiento del papel que juegan en el equilibrio del ecosistema, a la vez que se garantice su preservación. En este caso son las aves y los mamíferos los elementos más representativos, y los que mayor atractivo generan en la población que visita el parque. No obstante, es necesario realizar estrategias para revalorizar la percepción de los anfibios y reptiles.

\subsection{Análisis de Debilidades, Amenazas, Fortalezas y Oportunidades del turismo en el PEEC}

Para identificar las debilidades, amenazas, fortalezas y oportunidades de la implantación del turismo en el Parque se organizaron tres talleres con la comunidad, en los que se realizaron entrevistas no estructuradas e intercambio de opiniones entre los ejidatarios y el equipo de trabajo (Cuadro 4). Con la información generada se elaboró una matriz de correspondencia para identificar la estructura de la oferta y la demanda actual y potencialdel PEEC (Cuadro 5) y se establecieron los alcances de la propuesta de desarrollo turístico.

Aves: Otusflameolus(mochuelo rayado), Aegoliusacadicus(mochuelo afilador), Bubo virginianus(búho cornudo), Oreothlypiscrissalis(chipe de colima), Micrathenewhitneyi(búho elfo), Corvuscorax(cuervo), Cathartes aura (zopilote), Pipiloerythrophtalmus(pípilo), Falco sparverius(cernícalo américano), Falco peregrinus(cernícalo peregrino), Picoidesscalaris(carpintero mexicano), Picoidesvillosus(carpintero velloso mayor), Cardelina ruber(chipe rojo), Empidonaxhammondii(mosquero), Empidonaxoccidentalis(mosquero barranqueño), Hylocharisleucotis(colibrí).

Mamíferos: Didelphis virginiana (tlacuache), Mephitismacroura(zorrillo), Mustela frenata(hurón) y Neotomodonalstoni(ratón de campo). 


\section{Cuadro 4}

ANÁLISIS DAFO

\begin{tabular}{|l|}
\hline \multicolumn{1}{|c|}{ DEBILIDADES } \\
\hline 1. No tiene actividades definidas \\
2. Ausencia de mercado definido \\
3. Falta de recursos económicos \\
4. No cuenta con una mesa específica para la \\
administración del parque \\
5. Migración demográfica en búsqueda de \\
oportunidades
\end{tabular}

6. Desvalorización de la vida de campo

7. Débil capacitación de la población

\begin{tabular}{|ll|}
\hline \multicolumn{1}{|c|}{ FORTALEZAS } \\
\hline 1. & Ejido legalmente constituido \\
2. & Asamblea Ejidal participativa \\
3. & Iniciativa local para el desarrollo de proyec- \\
& tos productivos
\end{tabular}

4. Infraestructura turística básica

5. Zona con alto valor paisajístico

6. Cercanía con ciudades del valle de Toluca y México

7. Apoyo de las Instituciones Gubernamentales (Municipal, Estatal, Federal) y Académicas

8. Pertenecer a un Área Natural Protegida

9. Vínculos y alianzas estratégicas con dependencias gubernamentales, centro de educación e investigación científica, ONG y sociedad civil

\section{AMENAZAS}

1. Proceso de envejecimiento ejidal

2. Avance de la frontera agropecuaria y urbana

3. Extracción de productos forestales no maderables, como los hongos y la vara de perlilla, por personas ajenas al ejido

4. Erosión del suelo

5. Contaminación por el turismo desorganizado

6. Presencia de perros asilvestrados que han causado afectaciones a la fauna local

\section{OPORTUNIDADES}

1. Alto potencial para recibir turismo de naturaleza nacional y extranjero

2. Generación de empleos para los ejidatarios

3. Proyección para obtener recursos nacionales e internaciones para el cuidado de la fauna silvestre.

4. Establecimiento de una Estación Biológica

5. Vinculación con grupos deportivos

6. Consolidación de la Estación de Monitoreo y Sobrevivencia Invernal de Aves Migratorias (MoSI)

7. Establecimiento de una Unidad de Manejo para la Conservación de la Vida Silvestre (UMA)

8. Existencia de Programas Federales, Estatales y Municipales orientados al desarrollo y la conservación del Nevado de Toluca

9. Existencia de Programas Federales, Estatales y Municipales orientados al desarrollo y fortalecimiento comunitario

10. Cuentan con un grupo de ejidatarios que se están capacitando como guardaparques y guías turísticos 


\section{Cuadro 5 \\ MATRIZ DE CORRESPONDENCIA}

\begin{tabular}{|c|c|c|c|}
\hline Recursos reales & $\begin{array}{l}\text { Actividades e } \\
\text { infraestructuras } \\
\quad \text { reales }\end{array}$ & Recursos complementarios & $\begin{array}{l}\text { Actividades e infraes- } \\
\text { tructura complemen- } \\
\text { tarias }\end{array}$ \\
\hline $\begin{array}{l}\text { Área Natural } \\
\text { Protegida } \\
\text { Paisaje } \\
\text { Biodiversidad }\end{array}$ & $\begin{array}{l}\text { Zona de campa- } \\
\text { mento (refugios y } \\
\text { asadores) } \\
\text { Rutas de ciclismo, } \\
\text { senderismo. }\end{array}$ & $\begin{array}{l}\text { Avistamiento de flora y fauna } \\
\text { (especies bandera) } \\
\text { Paisaje } \\
\text { Observación de estrellas Cur- } \\
\text { sos y talleres } \\
\text { Educación Ambiental } \\
\text { Cultivos orgánicos y de hon- } \\
\text { gos comestibles } \\
\text { Comida típica/tradicional }\end{array}$ & $\begin{array}{l}\text { Estación biológica } \\
\text { Unidad de Manejo para } \\
\text { la Conservación de la } \\
\text { Vida Silvestre (UMA) } \\
\text { Turismo deportivo } \\
\text { Senderismo interpreta- } \\
\text { tivo } \\
\text { Cicloturismo } \\
\text { Centros de visitantes } \\
\text { Cabañas ecológicas }\end{array}$ \\
\hline Dema & a actual & Demanda po & otencial \\
\hline $\begin{array}{l}\text { Ciclistas, campis } \\
\text { general. }\end{array}$ & as y público en & $\begin{array}{l}\text { Instituciones educativas y de } \\
\text { nacionales e internacionales, } \\
\text { chers, deportistas amateur y de }\end{array}$ & $\begin{array}{l}\text { investigación, Ecoturístas } \\
\text { excursionistas, Birdwat- } \\
\text { alto rendimiento. }\end{array}$ \\
\hline \multicolumn{4}{|c|}{ Medios de difusión viables } \\
\hline \multicolumn{4}{|c|}{$\begin{array}{l}\text { Página de internet, vínculos en internet con dependencias gubernamentales, redes sociales, agen- } \\
\text { cias de viaje, revistas, radio y televisión, foros, convenciones, congresos, ferias ambientales, im- } \\
\text { presión de material de difusión. }\end{array}$} \\
\hline
\end{tabular}

\subsection{Propuesta de desarrollo turístico en el PEEC}

\subsubsection{Zonificación, ordenamiento y planeación de actividades}

Para el ordenamiento y planeación de las actividades turísticas se tomó como referencia la propuesta de zonificación elaborada por Sánchez-Jasso (2012) ${ }^{8}$, basada en la delimitación y evaluación de unidades de paisaje; y en donde se establecieron las siguientes subzonas de manejo de acuerdo con la Ley General Equilibrio Ecológico y Protección al Ambiente (LGEEPA, 2012): Preservación (P), Recuperación (R), Uso Público (UP) y Uso Tradicional (UT) (Figura 2). De acuerdo con los lineamientos establecidos para cada zona, las actividades turísticas sólo se proponen en las zonas de UP y UT.

8 La zonificación fue la base para desarrollar el «Proyecto de Rehabilitación y Ampliación de Infraestructura para el Desarrollo Sostenible en el PEEC», autorizado por la Secretaria de Medio Ambiente y Recursos Naturales (SEMARNAT) mediante oficio DFMARNAT/0035/2012. Además, se ha considerado para la elaboración del Programa de Manejo del PEEC, mismo que se encuentra en revisión en el momento de redactar estas páginas por las dependencias gubernamentales correspondientes. 


\section{Cuadro 6 \\ DEFINICIÓN DE SUBZONAS DE MANEJO}

\begin{tabular}{|c|c|c|}
\hline $\begin{array}{c}\text { SUBZONAS DE } \\
\text { MANEJO } \\
\text { (LGGEPA, 2012) }\end{array}$ & DEFINICIÓN & PROPUESTA DE ACTIVIDADES \\
\hline Preservación & $\begin{array}{l}\text { Sectores en buen estado de conser- } \\
\text { vación que contienen especies o } \\
\text { ecosistemas relevantes o frágiles, } \\
\text { en los que el desarrollo de activi- } \\
\text { dades requiere de un manejo es- } \\
\text { pecífico para lograr una adecuada } \\
\text { preservación. }\end{array}$ & $\begin{array}{l}\text { Únicamente se podrán realizar } \\
\text { actividades de bajo impacto, como } \\
\text { la investigación científica (estación } \\
\text { biológica y estación MoSI) y el me- } \\
\text { joramiento del ecosistema. }\end{array}$ \\
\hline Recuperación & $\begin{array}{l}\text { Sectores en los que los recursos } \\
\text { naturales han sido alterados o mo- } \\
\text { dificados y que deben ser objeto de } \\
\text { programas de recuperación o reha- } \\
\text { bilitación. }\end{array}$ & $\begin{array}{l}\text { En esta zona se podrán realizar ac- } \\
\text { tividades de bajo impacto como ma- } \\
\text { nejo, conservación y mejoramiento } \\
\text { del hábitat, investigación científica, } \\
\text { senderismo, cicloturismo,educación } \\
\text { e interpretación ambiental. }\end{array}$ \\
\hline Uso público & $\begin{array}{l}\text { Sectores que presentan atractivos } \\
\text { naturales para la realización de } \\
\text { actividades de ecoturismo, recrea- } \\
\text { ción, esparcimiento, educación e } \\
\text { interpretación ambiental. }\end{array}$ & $\begin{array}{l}\text { Es posible habilitar o rehabilitar la } \\
\text { zona de campamento y actividades } \\
\text { recreativas, mediante la infraestruc- } \\
\text { tura necesaria como cabañas ecológi- } \\
\text { cas, centro de visitantes, palapas para } \\
\text { días de campo, alberge para estu- } \\
\text { diantes, senderismo y cicloturismo. }\end{array}$ \\
\hline Uso tradicional & $\begin{array}{l}\text { Aquellas superficies en donde los } \\
\text { recursos naturales han sido apro- } \\
\text { vechados de manera tradicional, } \\
\text { sin ocasionar alternaciones signi- } \\
\text { ficativas en el ecosistema. Están } \\
\text { relacionadas particularmente con } \\
\text { la satisfacción de las necesidades } \\
\text { socioeconómicas y culturales de } \\
\text { los habitantes del área protegida }\end{array}$ & $\begin{array}{l}\text { Se podrán realizar actividades de } \\
\text { investigación científica, educación } \\
\text { ambiental y de turismo de bajo } \\
\text { impacto,así como la infraestructura } \\
\text { de apoyo que se requiera, utilizando } \\
\text { ecotécnias y materiales tradicionales } \\
\text { de construcción } \\
\text { propios de la región. Será posible } \\
\text { realizar prácticas de agricultura or- } \\
\text { gánica y producción de hongos sil- } \\
\text { vestres comestibles; senderismo y } \\
\text { cicloturismo. }\end{array}$ \\
\hline
\end{tabular}




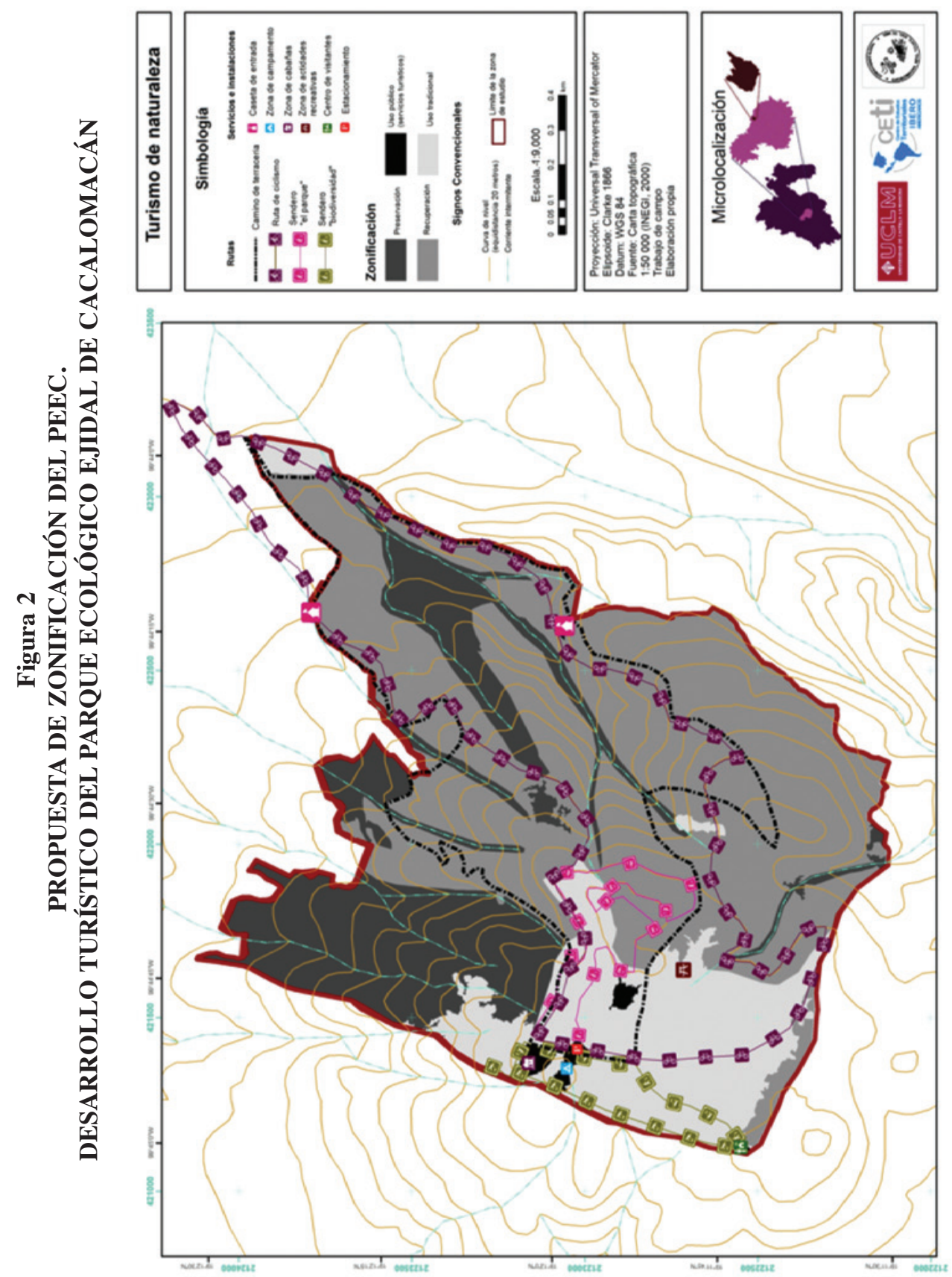




\subsubsection{Plan de acción: mapa de procesos}

Con objeto de articular un marco organizado de actuación sobre el Parque, se ha diseñado un plan de acción que contempla procesos estratégicos, operativos y de soporte. Tienen un carácter transversal, son de ámbito interinstitucional y se han planteado para que exista un participación activa de la comunidad local (San Martín Gutiérrez, 2005; Pérez Campdesuñer, 2006) (Cuadro 7).

Los procesos estratégicos tienen como objetivo articular un sistema administrativo práctico, funcional y eficaz, que garantice la instrumentación del plan de acción. Para ello la gestión interinstitucional es clave, ya que de ella depende lograr los recursos económicos y humanos necesarios. Entre las actividades contempladas se encuentra la gestión de los fondos económicos. La elaboración y seguimiento de las estrategias y programas de manejo, entre las que se incluye las autorizaciones en materia de impacto ambiental. Así como la puesta en marcha de servicios de marketing y diseño de la imagen corporativa; plan de negocios; servicios de comercialización, difusión y ventas, así como la creación de estructuras administrativas que aseguren la gestión y captación de los recursos financieros (locales y/o gubernamentales en el corto, mediano y largo plazo). En este apartado están incluidas las acciones de capacitación de los profesionales según perfiles y funciones asignadas. Finalmente está la promoción de una participación corresponsable por parte de la sociedad para salvaguardar el cumplimiento de las normas mediante la vigilancia y protección de los recursos naturales.

Los procesos operativos tienen la finalidad de fortalecer el capital social y de generar infraestructura turística. La puesta en funcionamiento de una administración exclusiva para el Parque tiene por objeto garantizar la presencia de prácticas de bajo impacto ambiental; adecuar, habilitar y construir infraestructuras destinadas a cubrir las necesidades de los usuarios;minimizar el impacto ambiental con la reglamentación de las actividades recreativas; difundir una cultura ambiental en los usuarios del parque mediante divulgación y educación; desarrollar y ejecutar un programa de interpretación ambiental; capacitar a guías e interpretadores de la naturaleza e instaurar una identidad en el parque empleando para ello las especies bandera.

Los procesos de soporte están orientados a labores estratégicas y operativas del plan de desarrollo. Se incluye el establecimiento de un centro de información externo, la elaboración de planes correctivos y preventivos; mecanismos de medición y análisis de la experiencia y satisfacción de cliente; convenios con instituciones y universidades para la generación de investigación básica y aplicada sobre las características, funcionamiento y conservación de la biodiversidad; puesta en marcha de una estación biológica que apoye las actividades de investigación y monitoreo, con capacidad para albergar a investigadores, estudiantes y voluntarios, así como la creación de una Unidad de Manejo para la conservación de la Vida Silvestre (UMA); la publicación de estudios e investigaciones de acuerdo a las características de aporte al conocimiento científico y al alcance que estos tengan; y la divulgación de resultados de estudios e investigaciones realizados en el parque a nivel local, regional, nacional e internacional. 


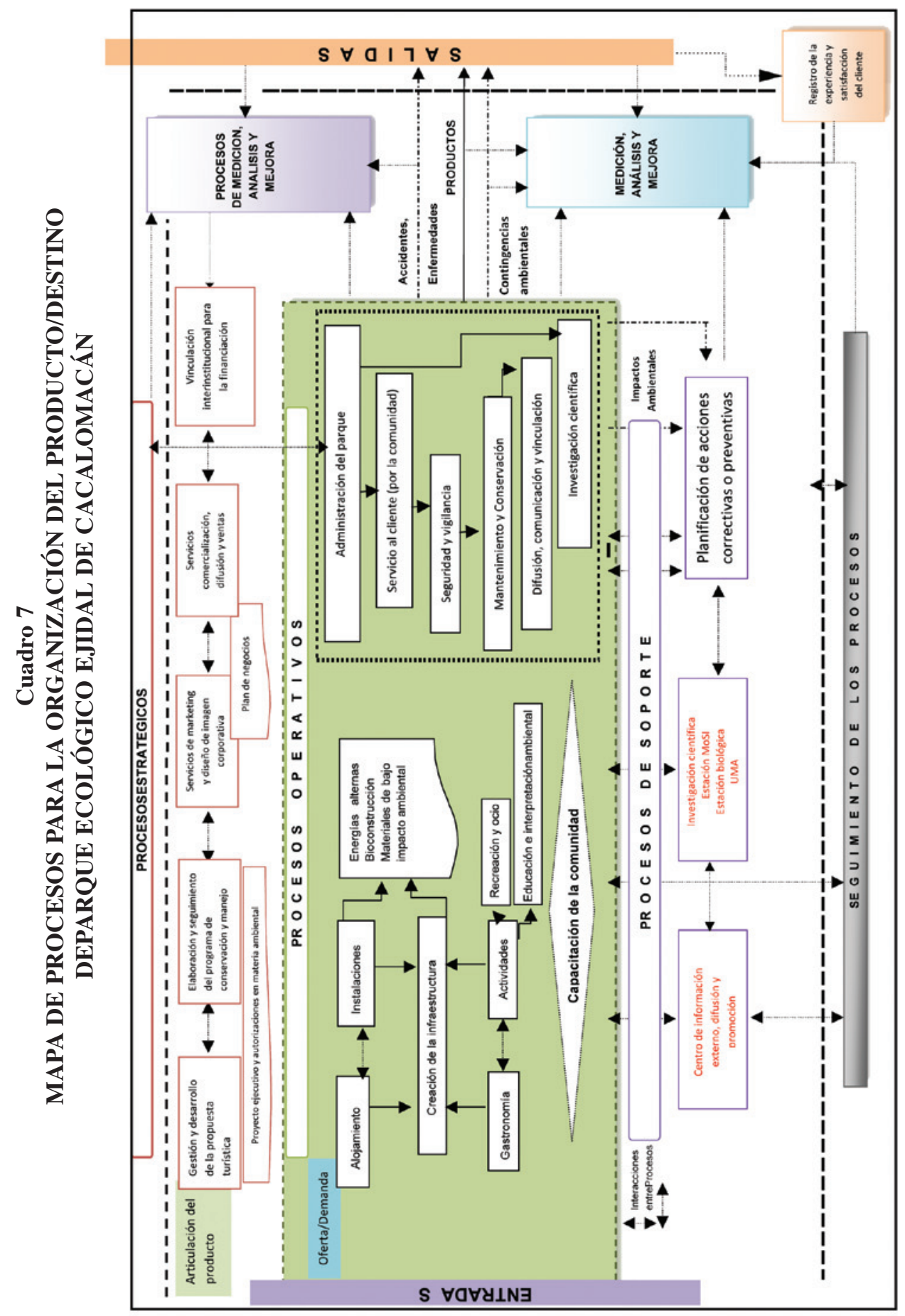

Cuadernos de Turismo, 36, (2015), 339-365 


\section{CONSIDERACIONES FINALES}

El turismo de naturaleza es una oportunidad de desarrollo local para las áreas protegidas de México, caracterizadas por la riqueza de su patrimonio natural y un peculiar y complejo contexto sociocultural. Pero su implantación exige de un tratamiento especial y cuidadoso para cada una de las partes del sistema turístico. Se hace necesario asumir los principios de conservación y aprovechamiento sostenible, y evitar que se convierta en un segmento más del mercado turístico,marcado en la mayor parte de los casos por esquemas e intereses puramente económicos (Bringas y Ojeda, 2000).

México cuenta con un elevado potencial para desarrollar actividades relacionadas con el aprovechamiento de los recursos naturales y culturales para uso turístico. A pesar de las controversias en algunos territorios, han surgido experiencias ilustradoras en comunidades o ejidos que administran directamente sus recursos y que han logrado impulsarlo con criterios de sostenibilidad (comunidad de «San Juan Nuevo Parangaricutiro» en Michoacán; «Ixtlán», «San Pedro El Alto» y la «Uzachi» en Oaxaca; «NohBec» en Quintana Roo, «Pueblo Nuevo» y «San Bernardino de Milpillas» en Durango), todos ellos con una certificación positiva por el buen manejo del bosque. Este modelo de empresa comunal ha permitido diversificar las actividades productivas, pero sobre todo han desarrollado proyectos de ecoturismo y gestión de recursos asociados al manejo de la vida silvestre. Los beneficios económicos obtenidos se han distribuido entre los integrantes de la comunidad, y han generado empleos y recursos que se destinan a obras de carácter social (acondicionamiento de caminos, creación de escuelas, centros sanitarios, regeneración de bosque o han apoyado la aparición de empresas productivas comunitarias). En todos los casos los conocimientos y las prácticas tradicionales se han enriquecido con estrategias de recuperación de especies y regeneración ambiental, se han impulsado procesos de transformación de las materias primas para su comercialización en mercados nacionales e internacionales, se han promovido procesos de certificación y etiquetado, han surgido nuevas marcas privadas y colectivas o se han creado denominaciones de origen. En muchos casos han generado beneficios económicos, pero también identidad y valor social $\left(\mathrm{CONABIO}^{9}, 2006\right)$. En definitiva, el capital social se ha comprometido con la conservación de los recursos naturales y con el desarrollo local.

El Nevado de Toluca (NT) comienza a convertirse en un destino turístico a nivel nacional e internacional. Aunque el perfil dominante de los visitantes ha ocasionado severos impactos ambientales, es posible desarrollar estrategias orientadas a corregir los desajustes detectados, y sobre todo dirigidas a mejorar el uso de los recursos territoriales turísticos. Hay que tener presente que las sociedades receptoras entienden el turismo como una estrategia de diversificación económica, que puede ayudar a mejorar la calidad de vida, conservar el patrimonio natural y cultural, y fomentar nuevas oportunidades apoyadas en la gestión integral de los recursos.

El presente trabajo propone un modelo de desarrollo turístico diseñado para el Parque Ecológico Ejidal de Cacalomacán. La metodología aplicada pretende equilibrar las preferencias de los turistas (jóvenes, familias, instituciones educativas y deportistas procedentes

9 CONABIO: Comisión Nacional para el Conocimiento y Uso de la Biodiversidad. 
en su mayoría del Estado de México, que realizan el viaje por medio propio y que actúan como visitantes de corta duración -apenas unas horas- con las costumbres y aspiraciones de las sociedades receptoras. Se trata de armonizar la preservación ambiental con la generación de empleo e ingresos económicos; promover la educación y cultura ambiental, conservando y restaurando el patrimonio natural, y evitar cambios de uso de suelo, uno de los principales factores que contribuyen al deterioro de los ecosistemas ecológicos, la diversidad biológica y los sistemas que sostienen la vida.

Desde la creación del parque, la oferta de actividades se limitó al ciclismo y los días de campo. Sin embargo el Parque cuenta con potenciales para impulsar nuevas actividades de turismo de naturaleza, como: la educación ambiental, la investigación, el turismo relacionado al deporte-salud y el diseño de senderos interpretativos y ruta de ciclismo, considerando, entre otras variables, la zonificación, la pendiente de terreno y la capacidad de carga (Sánchez-Jasso, 2011). En resumen, la diversificación de los productos y servicios, la dotación de infraestructura y equipamientos; el fortalecimiento, acompañamiento y capacitación del capital social en el corto, medio y largo plazo; así como la permanente y sistemática generación de conocimiento sobre el sistema territorial, son claves para consolidar al PEEC como un modelo de desarrollo turístico sostenible en el Nevado de Toluca.

El éxito de los proyectos comunitarios con miras hacia la sostenibilidad, dentro y fuera de los espacios protegidos, depende de la disponibilidad y voluntad de los actores implicados. El Ejido de Cacalomacán ha hecho una apuesta por la conservación de su patrimonio y ha impulsado alianzas estratégicas con instituciones académicas y organizaciones gubernamentales y no gubernamentales, que han aportado conocimiento, recursos humanos y económicos, con ello se ha abierto un proceso de cambio dentro del Nevado de Toluca, en donde la planificación y gestión de los recursos naturales -incluyendo el turismo-, debe tener como eje central la preservación del patrimonio natural, principal objetivo de las Áreas Protegidas a nivel mundial.

\section{AGRADECIMIENTOS}

Al Ejido de Cacalomacán, a la Universidad de Castilla la Mancha, al Centro de Estudios Territoriales Iberoamericanos; a la Universidad Autónoma del Estado de México,al H. Ayuntamiento de Toluca, a la Mtra. Mónica Vulling Garza, Mtra. Ana Margarita Romo Ortega, Mtra. Karina Ávila Islas, al Biól. Juan Pablo Medina Castro, a la M. en C. Xóchitl Aguilar Miguel, a la M. en G. Georgina Sierra Domínguez, por el apoyo y respaldo durante el desarrollo de la investigación.

\section{BIBLIOGRAFÍA}

ANTON CLAVÉ, S. y GONZÁLEZ REVERTE, F. (1997): «Opciones para el desarrollo sostenible de los espacios rurales» en Venezuela Rubio, M. (Coord.): Los turismos de interior. El retorno a la tradición viajera, Madrid, Ediciones de la Universidad Autónoma de Madrid, pp. 61-69.

ÁVILA BERCIAL. R., (2008): «Metodología básica para la evaluación ponderada de los recursos patrimoniales en su proceso hacia la conversión en productos turísticos».en 
Cebrián Abellán F. (Coord.): Turismo Rural y Desarrollo Local, Albacete, Ediciones de la Universidad de Castilla la Mancha, pp. 229-241.

ÁVILA ISLAS K., SÁNCHEZ-JASSO J. M., y VELÁZQUEZ AYALA A. (2012): «Áreas Naturales Protegidas del Municipio de Toluca: naturaleza, cultura y tradición». H. Ayuntamiento de Toluca 2009-2012. Toluca, Estado de México. 125 pp.

BOSH CAMPRUBÍ, R. et al. (1998): Turismo y medio ambiente. Madrid, Ed. Centro de Estudios Ramón Areces, 225 pp.

BRENNER, L. (2006):Áreas Naturales Protegidas y Ecoturismo: El Caso de la Reserva de la Biosfera Mariposa Monarca, México. Relaciones, XXVII, número 105. Colegio de Michoacán, México.

BRINGAS, N. y OJEDA, L. (2000):El Ecoturismo ¿Una nueva modalidad de Turismo de masas?, Economía, Sociedad y Territorio, vol. II, no 7, pp. 373-403.

CAPRA, L., NORINI, G., GROPPELLI, G., MACÍAS, J. L., \& ARCE, J. L. (2008): «Volcanic hazard zonation of the Nevado de Toluca volcano», Journal of Volcanology and Geothermal Research, vol176(4), pp. 469-484.

CEBAllos LASCURAÍN, HÉCTOR. (1999):Context: Perspectives and Definitions. Ponencia leída en el Diálogo sobre Turismo Sustentable en Áreas Naturales de América del Norte, 27-28 de mayo, Playa del Carmen, Quintana Roo, México. Citado en: Comisión para la Cooperación Ambiental. (2000): Avances en la promoción del turismo sustentable en áreas naturales protegidas de América del Norte.

CEBRIAN ABELLÁN A. (2008): «El Turismo Rural Sostenible»,en Cebrián Abellán F. (Coord.): Turismo Rural y Desarrollo Local, Ediciones de la Universidad de Castilla la Mancha, pp. 49-56.

CONABIO. (2006):Capital natural y bienestar social. Comisión Nacional para el Conocimiento y Uso de la Biodiversidad. México. 77 p.

COMISIÓN PARA LA COOPERACIÓN AMBIENTAL. (2000): Avances en la promoción del turismo sustentable en áreas naturales protegidas de América del Norte. Nota del Secretariado de la Comisión para la Cooperación Ambiental. Montreal. Canadá. 19 pp.

COMISIÓN NACIONAL DE ÁREAS NATURALES PROTEGIDAS. Áreas Naturales Protegidas. En: www.conanp.gob.mx. Fecha de consulta noviembre 2013.

COMISIÓN NACIONAL DE ÁREAS NATURALES PROTEGIDAS. Estudio Previo Justificativo para la recategorización del Nevado de Toluca. En: www.conanp.gob. mx. Fecha de consulta noviembre 2013.

COMISIÓN NACIONAL DE LA BIODIVERSIDAD (2011): En: www.conabio.gob.mx. Fecha de consulta marzo 2011.

CROSBY, A. (1993): «El desarrollo turístico sostenible en el medio rural», Madrid, Centro Europeo de Formación Ambiental y Turística, 268 pp. Citado en Cebrián Abellán F. (Coord.): Turismo Rural y Desarrollo Local, Albacete, Ediciones de la Universidad de Castilla la Mancha, pp. 49-56

DACHARY A. y STELLA A. (2002): «Globalización, Turismo y Sustentabilidad», Universidad de Guadalajara. México.

DALTABUIT G. M., CISNEROS L. y VÁZQUEZ, SANTILLAN E. (2000): «Ecoturismo y desarrollo Sustentable: Impacto en comunidades rurales de la selva maya». Centro Regional de Investigaciones Multidisciplinarias UNAM. México. 357 pp. 
DIARIO OFICIAL DE LA FEDERACIÓN (DOF): 1936. Decreto que declara Parque Nacional el «Nevado de Toluca, 15 de enero de 1936, México, D.F.

DIARIO OFICIAL DE LA FEDERACIÓN (DOF): 2013. Decreto que declara Área de Protección de Flora y Fauna Nevado de Toluca, 01 de octubre de 2013, México, D.F.

EAGLES, PAUL. (1999): Ecotourism Demand. Ponencia leída en el Diálogo sobre Turismo Sustentable en Áreas Naturales de América del Norte. Playa del Carmen, Quintana Roo, México. Citado en: Comisión para la Cooperación Ambiental. (2000): Avances en la promoción del turismo sustentable en áreas naturales protegidas de América del Norte.

EPLER, M. (2002): Ecotoutism: principles, practices and policies for sustainability. UnitedNationsEnvironmentProgramme (UNEP), Paris.

GARCÍA, E., (1981):Modificaciones al sistema de clasificación climática de Köeppen. Instituto de Geografía. Universidad Nacional Autónoma de México. México, D. F. $246 \mathrm{pp}$.

GARCÍA HENCHE B., (2008): «Características diferenciales del turismo rural y estrategias de comercialización», en Cebrián Abellán F. (Coord.): Turismo Rural y Desarrollo Local, Albacete, Ediciones de la Universidad de Castilla la Mancha, pp. 251-261.

GONZÁLEZ, M.J. y GARCÍA, J.C. (1998): «Fuentes documentales sobre desarrollo local», Anales de Geografía de la Universidad Complutense, n 18, pp. 337-353.

HUNTER, H. (1995): «On the need to re-conceptualisesustaible development» „Journal of Sustainable Tourism, n⿳3 (3), pp. 155-168.

IVARS et alt. (2001): Planificación y gestión del desarrollo turístico sostenible: propuestas para la creación de un sistema de indicadores. Universidad de Alicante. Alicante.

LEY GENERAL DEL EQUILIBRIO ECOLÓGICO Y PROTECCIÓN AL AMBIENTE. Diario Oficial de la Federación. 1998 (Reglamentos y Modificaciones 2004, 2012).

MADER, R. (2006):«Responsibletourism in theTuxtlas», Planeta, Global Journal of PracticalEcotourism, Sitio web accesado Julio 10 2007. http://www.planeta.com/ecotravel/ mexico/veracruz/tuxtlas.html.

MÁRQUEZ, D. (2008): «Fundamentos teóricos del desarrollo territorial y local. El capital social», en Cebrián, F. (Coord.): Turismo rural y desarrollo local. UCLM, Universidad de Sevilla. Cuenca, pp. 67-75.

MCNEELY, J.A. y JEFFERY A. (1999):Tourism and Biodiversity: Making the Natural Partnership Effective.Ponencia leída en el Diálogo sobre Turismo Sustentable en Áreas Naturales de América del Norte. Playa del Carmen, Quintana Roo, México. Citado en: Comisión para la Cooperación Ambiental. (2000). Avances en la promoción del turismo sustentable en áreas naturales protegidas de América del Norte.

MOLLARD,A. (2001): «Qualité et développement territorial: une grille d'analysethéorique à partir de la rente», Économierurale, n 263, pp. 16-34.

NAREDO, J.M (1996): «Sobre el origen, el uso y el contenido del término sostenible»,Documentación social, $\mathrm{n}^{\circ}$ 102, pp. 129-147.

NAREDO, J.M. (2004): «Crecimiento insostenible, desarrollo sostenible», en Romero J. (Coord.) Geografía Humana, Barcelona. p.p 395-447. 
NIEVA, A. (2005): DDiagnóstico del Ecoturismo en el Contexto de México», Planeta, Global Journal of PracticalEcotourism, Sitio web accesado 18 Julio 2007. http://www. planeta.com/planeta/02/0203diagnostico.html

OMT (1993): Indicators for the sustainable management of tourism. OMT. Madrid.

OSORIO-GARCIA M., FRANCO MASSS S., RAMÍREZ DE LA O I., NAVA BERNAL G., NOVO-ESPINOSA G. y REGIL HÉCTOR H. (2011): «El visitante del Parque Nacional Nevado de Toluca, México. Análisis del comportamiento en un área natural protegida», Investigaciones Geográficas, Boletín del Instituto de Geografía, UNAM, $\mathrm{n}^{\mathrm{o}} 76$, pp. 56-70.

ORGANIZACIÓN MUNDIAL DE TURISMO (1991): «Conferencia Internacional de Estadísticas de Turismo y Viajes», Ottawa, Canadá. Citado en en Secretaría de Turismo, Programa Nacional de Turismo 2001-2006, México, 2001.

ORGANIZACIÓN MUNDIAL DE TURISMO (1995): Carta Mundial del Turismo Sostenible, Madrid, $146 \mathrm{pp}$.

ORGANIZACIÓN MUNDIAL DE TURISMO (2002): Cumbre Mundial del Ecoturismo. Informe final. Quebec, Candada. $148 \mathrm{pp}$.

ORGANIZACIÓN MUNDIAL DE TURISMO (2002): Tendencias de los mercados turísticos: las Américas, Madrid, $356 \mathrm{pp}$.

PECQUEUR, B. (2001): «Qualité et développement territorial: l'hypothèse du panier de biens et de servicesterritorialisés», Économierurale, vol. 261(1), pp. 37-49.

PÉREZ CAMPDESUÑER R. (2006): «Modelo y procedimientos para la gestión de la calidad del destino turístico Holguinero». Tesis de Doctorado. Universidad de Holguín. Facultad de Ingeniería Industrial.

PULIDO, J.I. (2005): Criterios para una política turística sostenible en los parques naturales de Andalucía. Consejería de Turismo, Comercio y Deporte. Junta de Andalucía.

SAN MARTÍN GUTIÉRREZ H. (2005): «Estudio de la imagen de destino turístico y el proceso global de satisfacción: Adopción de un enfoque integrador».Tesis de Doctorado. Universidad de Cantabria. Departamento de Administración de Empresas. España.

SÁNCHEZ JASSO J.M. (2011): Turismo de naturaleza en el Parque Ecológico Ejidal de Cacalomacán. Tesis de Master en Turismo Rural y Desarrollo Local. Universidad de Castilla la Mancha. Albacete.

SÁNCHEZ JASSO J.M. (2012): Estrategia para la conservación del Parque Ecológico Ejidal de Cacalomacán. Parque Nacional Nevado de Toluca. Tesis de Maestría. Posgrado en Ciencias Agropecuarias y Recursos Naturales. Universidad Autónoma del Estado de México.

SÁNCHEZ-JASSO J.M., AGUILAR-MIGUEL, X., MEDINA CASTRO, J.P. y SIERRA DOMÍNGUEZ G. (2013):»Riqueza de vertebrados de un Bosque Reforestado del Parque Nacional Nevado de Toluca»,Revista Mexicana de Biodiversidad, vol. 84 (1), pp. 360-373.

SECRETARÍA DE TURISMO (2001): Estudio Estratégico de Viabilidad del Segmento de Ecoturismo en México, Resumen Ejecutivo. Centro de Estudios Superiores en Turismo (CESTUR), Diciembre 2001, México D.F.

SECRETARÍA DE TURISMO. Programa Nacional de Turismo 2001-2006, México. 
SECRETARÍA DE TURISMO. (2007): «Como desarrollar un proyecto de ecoturismo», 2 da edición. México. Distrito Federal.

SECRETARÍA DE TURISMO. (2004): «Turismo Alternativo». México. Distrito Federal.

SIERRA-DOMÍNGUEZ G. (2013):Áreas Protegidas de América Latina y la ocupación humana, México una diferencia. Reencuentro de Saberes Territoriales Latinoamericanos. Perú. Sitio consultado el 26 noviembre de 2013. http://www.egal2013.pe/wpcontent/uploads/2013/07/Tra_Georgina-Patricia.pdf

SKREI, S. (1998): «Supporting Grassroots Ecotourism efforts in Central Mexico», Planeta, Global Journal of Practical Ecotourism, Sitio web consultado el 19 Julio 2007. http:// www.planeta.com/planeta/98/0298greenmex.html

WEARING, STEPHEN, AND JOHN NEIL. (1999):Ecotourism: Impacts, Potentials and ANTON CLAVÉ, S. Y GONZÁLEZ REVERTE, F. (1997): «Opciones para el desarrollo sostenible de los espacios rurales» en Venezuela Rubio, M. (Coord.): Los turismos de interior. El retorno a la tradición viajera, Madrid, Ediciones de la Universidad Autónoma de Madrid, pp. 61-69. 
